\title{
Using $\mathrm{ZnO}$ nanoparticles in fungal inhibition and self-protection of exposed marble columns in historic sites
}

\author{
Mohammad Ateeq Aldosari ${ }^{1}$ - Sawsan S. Darwish ${ }^{2} \cdot$ Mahmoud A. Adam $^{2} \cdot$ Nagib A. Elmarzugi $^{3,4} \cdot$ Sayed M. Ahmed $^{5}$
}

Received: 18 July 2018 / Accepted: 29 November 2018 / Published online: 4 January 2019

(C) The Author(s) 2019

\begin{abstract}
The marble columns at many historic sites represent one of the most important and fundamental architectural elements in a building. They are almost always subject to serious damage, whether in the base, middle, or crowns of columns by fungal infection. In most cases, the microbial deterioration affects the physical and mechanical properties of historic marble columns, which have in turn been affected by other damaging factors (e.g., weathering from the elements or mechanical damage), leading to their partial or total collapse. In this current study, researchers are turning to new technologies in order to find the ideal solution to inhibit fungal growth, and, in turn achieve the total protection of exposed historic marble columns. The photocatalytic inorganic nanoparticles of $\mathrm{ZnO}$ have been employed for the purpose of long-term protection of exposed marble columns by inhibiting microbial-fungal attack and forming a protective surface layer. $\mathrm{ZnO}$ nanoparticles were dispersed in laboratory synthesized acrylic polymer to create a combined biocidal and consolidating coating to be applied on historic marble columns substrate. The synthesized nanocomposite coating was characterized and applied to marble samples collected from various archeological sites in Egypt. The protecting effect of synthesized nanocoating against fungal attack by Aspergillus niger and Penicillium sp., in addition to RH/Temperature, UV aging, and mechanical deterioration, was studied. The consolidating action of the obtained mixtures was evaluated through microscopic examination and capillary water absorption. Further, colorimetric measurements have been performed to evaluate the optical appearance of the columns. $\mathrm{ZnO}$ nanocomposites displayed better performance when compared to the pure synthesized acrylic polymer. The coated $\mathrm{ZnO}$ nanoparticles enhanced the durability of stone surface to resist the fungal attack when subjected to inoculums containing Aspergillus niger and Penicillium sp. and improved the resistance to UV aging, relative humidity, and thermal effect compared to the samples coated with the acrylic polymer without $\mathrm{ZnO}$ nanoparticles. Self-protection properties were confirmed without any obvious color changes on marble surfaces.
\end{abstract}

Keywords $\mathrm{ZnO}$ nanocomposites $\cdot$ Biocidal remedy $\cdot$ Fungal inhibition $\cdot$ Historic sites $\cdot$ Marble columns $\cdot$ Self-protection

\section{Introduction}

Through the centuries, the exposed marble columns in historic buildings have deteriorated, due to physiochemical and

Mohammad Ateeq Aldosari

aldosari@kacst.edu.sa

Sawsan S. Darwish

sawsansd@hotmail.com

Mahmoud A. Adam

hafezm762000@yahoo.com

Nagib A. Elmarzugi

nelmarzugi@gmail.com

Sayed M. Ahmed

sayedmansour32@yahoo.com mechanical factors such as rain water, sunlight, wind, frost, and excess loads (Winkler 2002). Moreover, the microbiological deterioration of historic stone buildings and their architectural elements represents a serious threat for their future

1 National Nanotechnology Research Center, King Abdulalziz City for Science and Technology (KACST), P.O. Box 6086, Riyadh 11442, Saudi Arabia

2 Department of conservation, Faculty of Archaeology, Cairo University, P.O. Box 12613, Giza 12221, Egypt

3 Faculty of Pharmacy, Tripoli University, P.O. Box 13100, Tripoli, Libya

4 National Nanotechnology Project, Biotechnology Research Center, LARST, P.O. Box 13100, Tripoli, Libya

5 Ministry of Antiquities, The grand Egyptian Museum, Giza 12556, Egypt 
existence (Macedo et al. 2009; Rebricova 1991). The growth of microorganisms such as fungi, algae, and bacteria on the stone surface and internally is usually linked to the ideal environmental conditions in terms of light, food, temperature, and moisture, as well as by the chemical nature of the substratum (Gorbushina et al. 1993). Microbiological deteriogens can play a pivotal role in the deterioration of architectural marble elements of historic buildings by a variety of mechanisms, such as powdering, cracking, and biocorrosion caused by the excretion of corrosive organic and inorganic acids. In addition, the formation of black biofilm on stone surfaces can lead to the partial or full loss of stone monuments and disfigurement of building stone material (Abdelhafez et al. 2012; Farooq et al. 2015; Monte 2003).

The protection and bioconservation of these historic elements is an important target (Ditaranto et al. 2011). In the last five decades, conservation strategies have usually relied upon the use of the synthetic polymeric coatings to protect the stone surface, hence the bioreceptivity (Bracci and Melo 2003; Johnson and Mclntyre 1996), and on the application of biocidal products to inhibit biological activity. Acrylic copolymers in particular Paraloid B-44 and Paraloid B-72 have been widely used for creating self-protection stone coatings that are extremely stable to degradation by ultraviolet, heat, and oxidation. However, these polymeric coatings can be subjected to degradation by microorganism attack, and the fungal growth interfered with the structural fabric of the polymer, modifying their hydrophobic properties (McNeill 1992; La Russa et al. 2012; Ruffolo et al. 2010). Conventional conservation strategies typically rely on the use of water repellents to reduce water absorption, hence the bioreceptivity and upon the application of biocidal products to inhibit biological activity (Nugari and Pietrini 1997; Moreau et al. 2008). Unfortunately, the improper interaction between the biocide and the water-repellent material may occur when separately applied to the substrate. These challenges and drawbacks in polymeric materials have attracted the attention of conservation experts to use the modern techniques of other sciences to increase the efficacy of the conventional methods to achieve higher consolidation and protection efficiency (Malagodi et al. 2000; Urzi and De Leo 2007; Muynck et al. 2009).

Therefore, some recent studies have focused on other innovative strategies in order to overcome some of these drawbacks. Among them, the possibility of embedding the photocatalytic nanoparticles in polymeric matrices to obtain bioactive coating with self-cleaning and consolidating properties aimed at the long-term preservation of marble stone monuments have been pursued (Frank-Kamenetskaya et al. 2010; Pinna et al. 2018). There is an immediate need to develop alternative multifunctional surface protection coating capable of acting as a remedial conservation and to prevent microbial deterioration in one step (Shilova et al. 2009; Monteiro et al. 2009). Recently, in the field of building material and stone conservation, photocatalytic treatments based on photoactive nanomaterials have been set up as an effective strategy to reduce the accumulation of pollutants, biofilm, and particulate matter on architectural surfaces with a decrease in the esthetical and chemical decay over time (Aldosari et al. 2017a, b). The marked biological and self-protection activity of the nanomaterials against a wide range of different living microorganisms using various semiconductors is well known (Dutta et al. 2012). Metals and metal oxide nanomaterials, e.g., $\mathrm{TiO}_{2}$, $\mathrm{Ag}, \mathrm{MgO}$, and $\mathrm{CaO}$ are receiving significant scientific attention due to their vast existing, as well as potential newer applications, especially as biocidal and self-protection coatings have hydrophobic and consolidation properties (Nations et al. 2011). These materials have longer life spans as compared to organic antimicrobial agents and are chemically stable in extreme conditions. Moreover, these nanomaterials attack a broad range of targets in microorganisms, thus avoiding the development of resistance (Zhang et al. 2010). The possibility of embedding nanoparticles such as copper nanoparticles, $\mathrm{SiO}_{2}$, and $\mathrm{TiO}_{2}$ in inert polymeric matrices to obtain nanostructured bioactive coatings for different applications has been reported by the authors in various studies (Kapridaki and Maravelaki-Kalaitzaki 2013; Cioffi et al. 2004; Cioffi et al. 2005). In another study, the preparation and characterization of antimicrobial surfaces made by combining $\mathrm{Ca}(\mathrm{OH})_{2}$ suspensions with titania or zinc oxide nanoparticles for the conservation of limestone monuments has been reported (Gomez-Ortez et al. 2013; Van der Werf et al. 2015).

In this regard, zinc oxide nanoparticles (ZnO-NPs) have attracted the interest of the scientific community for their multifunctional properties: biocompatibility, bioactivity, and chemical stability. With regard to the bioactivity, ZnO-NPs have been demonstrated to be effective in killing both Gram-positive and Gram-negative bacteria and also in inhibiting the growth of fungi (Lipovsky et al. 2011; Ditaranto et al. 2015). ZnO-NPs are one of the most efficient photocatalyst material; they were found to versatile and considered to be the new potential next-generation material as self-protection, and biocidal or disinfecting agents (Espitia et al. 2012), which are attributed to the role of reactive oxygen species (ROS) generated on the surface of the particles (Golego et al. 2000). These new treatments of zinc ion release (Jayaseelan et al. 2012) and nanoparticle internalization (He et al. 2011) are the subject of this study. Since $\mathrm{ZnO}$ has almost the same band gap energy $(3.2 \mathrm{eV})$ as $\mathrm{TiO}_{2}$, their photocatalytic capacity is anticipated to be similar to that of $\mathrm{TiO}_{2}$. Moreover, some studies have confirmed that $\mathrm{ZnO}$ exhibit a better efficiency than $\mathrm{TiO}_{2}$ in photocatalytic degradation of some dyes, even in an aqueous solution (Sawai and Yoshikawa 2004). The photocatalyst, $\mathrm{ZnO}$, has been used in the degradation and complete mineralization of environmental pollutants (Sharma et al. 2010). Furthermore, $\mathrm{ZnO}$ nanoparticles are able to decompose and mineralize bio-recalcitrant organic pollutants in the form of $\mathrm{CO}_{2}$ and $\mathrm{H}_{2} \mathrm{O}$ (Moafi et al. 2011). 
Therefore, the aim of this current study is to investigate the photocatalytic efficiency of $\mathrm{ZnO}$ nanoparticles dispersed in synthesized polymeric matrix as biocidal and self-protection coatings applied to deteriorated marble stone surfaces. This work presents a novel experimental laboratory study concerning the possibility of the use of a lab-synthesized acrylic polymer embedded by the nanoparticles to obtain a new nanocomposite by in situ emulsion polymerization method and the possibility for its application for the conservation of historic marble stone. In order to evaluate the efficiency of the coating, isolation of fungal species from deteriorated surface was carried out using a sterilized sticking tape and analyzed to understand the corrosive effects of microbial colonization on the stone material. After that, a semi-quantitative method assessed the biocidal efficiency of the pure polymer and nanocomposite coatings, detecting the growth inhibition of Penicillium sp. and Aspergillus niger colonies on the stone surface. Surface morphology, before and after treatment, and the penetration of nanoparticles within the stone materials were examined by scanning electron microscopy (SEM), and changes in the molecular structure occurring in treated samples before and after aging were studied using Fouriertransform infrared spectroscopy-attenuated total reflectance (FTIR-ATR). Capillary water absorption and colorimetric measurements have also been conducted.

\section{Materials and methods}

\section{Materials}

\section{Laboratory synthesis of coating materials}

An acrylic resin, similar to Paraloid B-44, was synthesized. Paraloid B-44 is an acrylic co-polymer based on methyl methacrylate and ethyl acrylate. It was chosen as a dispersing medium of $\mathrm{ZnO}$ nanoparticles; it is one of the major materials used to form hard coating for protecting art works. $\mathrm{ZnO}$ nanopowder (with particle mean diameter of $40 \mathrm{~nm}$ ) was obtained from Sigma-Aldrich, Munich, Germany and used as received.

The acrylic resin used in this study was synthesized at concentration $(2 \% \mathrm{w} / \mathrm{v})$ and $\mathrm{ZnO}$ nanopowder was dispersed in synthesized Paraloid B-44 (Polymer 2\% w/v, ZnO $0.04 \mathrm{~g}$ ) (Ruffolo et al. 2010; La Russa et al. 2012). The synthesis process of $\mathrm{ZnO}$ nanoparticles/polymer nanocomposite has been prepared by in situ emulsion polymerization system, which was the first method used to synthesize polymer/ nanocomposites based on polyamide 66 (Feng and Leonardo 2006; Mohamed et al. 2009) (Fig. 1). The procedure consisted of synthesis of the acrylic polymer with fixed concentration $2 \%$ $w / v$ (solid content $2 \mathrm{~g} / 100 \mathrm{~mL}$ ), then $0.04 \mathrm{~g}$ of $\mathrm{ZnO}$ nanoparticles was added during the synthesis of the polymer to make the concentration of the nanoparticles in nanocomposites equal to $2 \% \mathrm{w} / \mathrm{v}$. The $\mathrm{ZnO}$ nanoparticle concentration depends on polymer solid content (Aldosari et al. 2017a, b) (see Table 1).

On completion of the mixture process, the obtained nanocomposites were characterized by transmission electron microscopy (TEM); Tecnai G20, Super twin, double tilt, electron accelerating voltage $200 \mathrm{kV}$ using lanthanum hexaboride (LaB6) electron source gun, and the diffraction pattern imaging (the examination was carried out in TEM lab, Agriculture Research Center, Cairo University, Cairo, Egypt).

\section{Preparation of experimental marble samples and application of nanocoatings}

$5 \mathrm{~cm} \times 5 \mathrm{~cm} \times 5 \mathrm{~cm}$ of cuboid Carrara marble samples were used. The samples were polished, washed with distilled water, and dried in an oven at $105{ }^{\circ} \mathrm{C}$ for at least $24 \mathrm{~h}$ to reach a constant weight. Then, the samples were left to cool at room temperature and controlled relative humidity $(\mathrm{RH}) 50 \%$, and then weighed again (Licciulli et al. 2011).

The application of nanocoatings on marble samples has been carried out by brushing them at room pressure and temperature. The operation was repeated three times within $2 \mathrm{~h}$ between each application (Aldosari et al. 2017a, b). After that, the samples were left to dry off for 1 month at room temperature and a controlled relative humidity (RH) of 50\% (Bakr 2011). Some samples were submitted for microbiological tests and the others were submitted to the artificial aging and investigation methods.

\section{Methods}

\section{Isolation of fungi colonies from the deteriorated historic marble surface}

The fungal isolation process was carried out on fungi samples collected from microbial infected marble surfaces of archeological marble columns in Amr ibn al-As mosque (641-642 AD), Al-Mansur Qalawun complex (12841285 AD), and Al-Tunbugha Al-Maridani mosque (13381339 AD) in the historic Cairo, Egypt (Fig. 2).

Two types of samples were collected from the infected marble: (1) Sterilized cotton swabs were used for isolation of fungi from the surface of infected marble. Then, they were kept in a sterile bag until laboratory inoculation. The collected samples were then transferred right onto two prepared media $\{$ DG18 \& Potato Dextrose Agar (PDA) $\}$. Plates were then incubated at $28-30{ }^{\circ} \mathrm{C}$ for $1-7$ days, depending on the microorganism (Strzelczyk 2004; Gilman 1974). (2) Carefully, small hard crusts were scratched from the infected marble surfaces by a sterile spatula, kept in sterile bag, and used as collected for microscopic investigation to understand the effect of microbial growth on stone structures. 
Fig. 1 The different steps of nanocomposite preparation by in situ polymerization technique

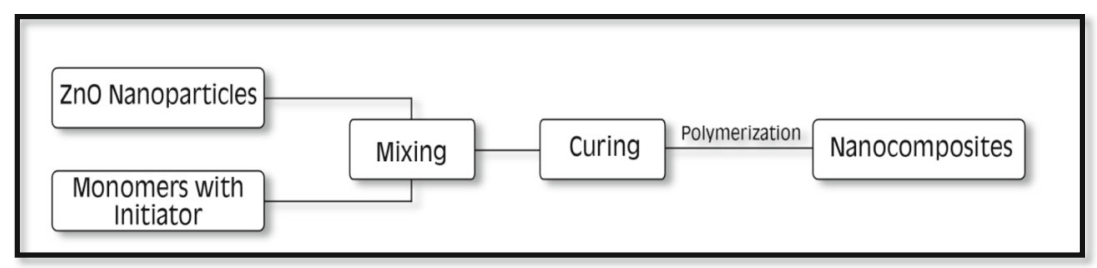

\section{Identification and examination of isolated fungi}

Plates of DG18 and Potato Dextrose Agar (PDA) were inoculated with each isolated sample and incubated for 1-7 days at $28^{\circ} \mathrm{C}$. The grown colonies were purified on the same medium and each single colony incubated was picked for identification (Domsch et al. 2008). A light microscope (Ziess 2010 Microscope with analysis unit) was used for studying the macro morphological and micro morphological features of taxonomic. The identification of isolated fungi was done with the help of reference standard and work (Cooke 1963). SEM microscope was used for investigation of the infected marble hard crust samples to evaluate the role of microorganism activity in promoting stone deterioration.

\section{Inoculation of the experimental samples with A. niger and Penicillium sp. fungi}

Untreated and treated experimental marble surfaces were inoculated with fungi colonies to evaluate the biocidal efficiency of the coating materials by observing the microbial growth on the surface. Aspergillus niger and Penicillium sp. fungi were chosen because they are among the most common airborne fungi, and the most common microorganisms living in rocks, and stone works, in addition to their ability to degrade the stone monuments (Nilsson 1983). The tested fungal strains were inoculated in Dox's agar plates, putted inside an incubation chamber at $28{ }^{\circ} \mathrm{C}$ for 7 days. Spore suspension was prepared by adding $10 \mathrm{~mL}$ of sterilized saline solution $(8.5 \mathrm{~g}$ $\mathrm{NaCl} / \mathrm{L} \mathrm{H}_{2} \mathrm{O}$ ) to each plate and then spores were scraped with a brush and used (Diakumaku et al. 1994; Matysik et al. 2008).

Once the fungi series had developed, $500 \mathrm{~L}$ of suspension was put on experimental marble surface. Series 1 (uncoated marble samples and samples coated with the polymer with or without $\mathrm{ZnO}$ nanoparticles) was inoculated with A. niger culture. Series 2 (uncoated marble samples and samples coated with the polymer with or without $\mathrm{ZnO}$ nanoparticles) was inoculated with Penicillium sp. culture. And then, all the samples were put in incubated chamber at $28^{\circ} \mathrm{C}$ during 4 weeks, for greater accuracy (Lopez and Gomez 1996). Experiments for each fungi colony were performed in triplicate before and after coating and checked each 3 days to observe the inhibition ratio.

\section{Morphological characterization by SEM}

SEM observation of uncoated, coated, and coated aged experimental marble samples was performed through scanning electron, Philips (XL30), (the examination was carried out in SEM lab, Housing and Building National Research Center, Cairo, Egypt). The characterization was performed to evaluate the distribution behavior of coating materials on stone surfaces and surface morphology. Images were acquired in backscattered mode (BSE).

\section{Artificial thermal and UV aging tests}

The above tests were carried out in order to evaluate the stability of the self-protection and hydrophobic properties of the coating materials. Thermal aging tests were carried out by subjecting the treated samples to 30 cycles of immersion and drying as follows: $18 \mathrm{~h}$ of total immersion in distilled water, then $6 \mathrm{~h}$ in a temperature-controlled oven at $105{ }^{\circ} \mathrm{C}$ (Lazzari and Chiantore 2000). Accelerated UV aging tests were performed through light emitted by a luminaire C.T.S. Art lux 40 with 2 UV fluorescent tubes $(5000 \mathrm{~K}, 45-\mathrm{cm}$ long, $100 \mathrm{~W}$, 220 ), with plexiglas protection screen, with a UV-A component, whose UV intensity was $2 \mathrm{~W} / \mathrm{cm}^{2}$. The distance between samples and the light source was $20 \mathrm{~cm}$. The samples were left under UV irradiation for 45 days (Malešič et al. 2005).

\section{Fourier-transformed infrared (ATR-FTIR) spectroscopy}

The analysis of ATR-FTIR spectra were processed on Attenuated total reflection Fourier Transform Infrared (ATR-
Table 1 Concentrations of used coating materials

\begin{tabular}{lllll}
\hline Coating material & $\begin{array}{l}\text { ZnO nanoparticles } \\
\text { concentration }(w / v)\end{array}$ & $\begin{array}{l}\text { ZnO solid } \\
\text { content }(\mathrm{g})\end{array}$ & $\begin{array}{l}\text { Polymer solid } \\
\text { content }(\mathrm{g})\end{array}$ & $\begin{array}{l}\text { The obtained } \\
\text { nanocomposite }\end{array}$ \\
\hline Paraloid B-44 & - & - & 2 & $\begin{array}{l}\text { Zero composite } \\
\text { ZnO nanoparticles }\end{array}$ \\
$2 \%$ & 0.04 & 2 & $\begin{array}{c}\text { ZnO nanoparticles/polymer } \\
\text { nanocomposites (2\%) }\end{array}$ \\
\hline
\end{tabular}



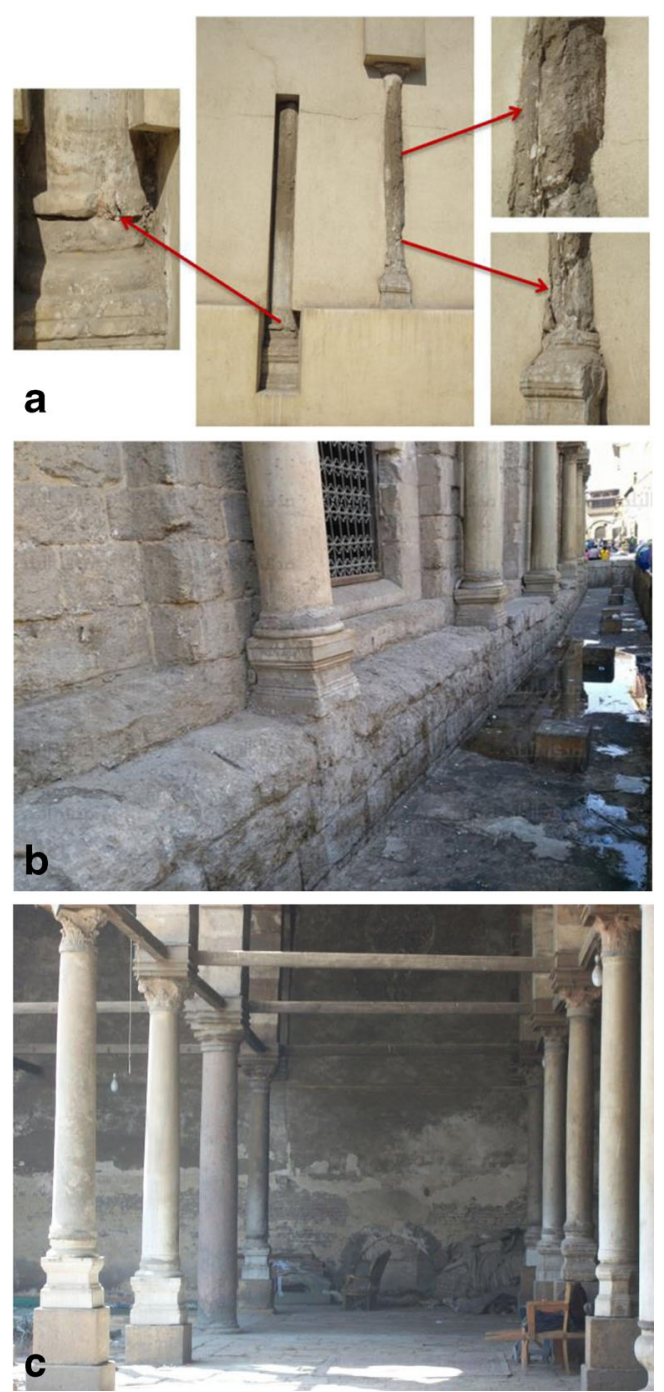

Fig. 2 Exposed marble columns in the historic studied buildings show the microbial infected marble surfaces. a Amr ibn al-As mosque, b AlMansur Qalawun complex, and c Al-Tunbugha Al-Maridani mosque

FTIR) Spectroscopy. ATR-FTIR was used for observing the changes in chemical bonding structure of treated samples during accelerated artificial ageing. All measurements were carried out at the same spot within the same samples, so that the results can be comparable. ATR-spectra were processed on BRUKER'S VERTEX 70-Attenuated Total Reflection Fourier Transform Infrared Spectroscopy (ATR-FTIR spectrometer) in the 650 $4000 \mathrm{~cm}^{-1}$ range, with a resolution of $4 \mathrm{~cm}^{-1}$. The vibrational bands that appear in the infrared spectra provided information about the chemical functional groups of a sample which led us to study changes in characterization of the materials.

\section{Colorimetric tests}

Colorimetric measurements of uncoated, coated, and coated marble samples after artificial aging were carried out using a CM2600d Kon-ica Minolta spectrophotometer, New York, United
States of America (USA), to evaluate the effect of the coating on the optical appearance of stone. Chromatic values are expressed in the CIE L*a*b* space, where $L^{*}$ is the lightness/darkness coordinate, $\mathrm{a}^{*}$ the red/green coordinate $\left(+\mathrm{a}^{*}\right.$ indicating red and $-a^{*}$ green), and $b^{*}$ the yellow/blue coordinate $\left(+b^{*}\right.$ indicating yellow and $-b^{*}$ blue). The instrument was set to automatically give the average value of three measurements for each point. Measurements were performed on the same points before and after coating and aging (CIE Standard 2007).

\section{Physical properties measurements (hydrophobic properties)}

Physical properties' values were tested and recorded in order to evaluate the hydrophobic and consolidating activities of coating materials. Two types of measurements, mentioned below, were conducted sequentially as follows.

Static contact angle measurement Contact angle measurements were carried out in order to determine the wettability by means of custom apparatus made in compliance with standard UNI EN $15802-2010$ (Helmi and Hefni 2014). This test was performed on the marble samples before and after coating. A high-resolution Canon camera with 18-55 lens and equipped with software program to calculate the contact angles values was used to capture the images of water droplets on the marble surface.

Capillarity water absorption test Measurements of water absorption were performed by capillarity which evaluates the amount of water absorbed by a stone specimen per surface unit. This test was performed using the gravimetric method on three samples for each stone species before and after coating and after artificial aging applying the two coatings, according to the following standard (UNI 10859:2000, Cultural Heritage - Natural and artificial stones - determination of water absorption by capillarity (UNI 10859. 2000)). The percentage of absorbed water was calculated using the following equation:

Water absorption $=\frac{W 2-W 1}{W 1} \times 100=\ldots \%$.

where $(W 1)$ is the mass of the specimen before immersion.

(W2) is the mass of the specimen after total immersion in water for $24 \mathrm{~h}$.

\section{Results and discussion}

\section{Identification of fungi isolates from the historic marble surface}

Three samples were isolated by swabs from three different marble columns at the historic sites studied. Sampling results 
showed the presence of numbers of fungi; the examination and characterization of the resulted fungal colonies showed nine fungal species belonging to four different genera which were identified as: Aspergillus, Penicillium, Cladosporium, and Ulocladium (Table 2). Isolates of each genus were subjected to species characterization based on morphological characteristics. From the results of genera identification and microscopic characterization and according to morphology, it can be seen that genus Aspergillus niger was the most predominant organism isolated from all swabs of deteriorated marble followed by Penicillium sp. and Cladosporium sp., as shown in Fig. 3.

\section{Investigation of the microbial deterioration effect on historic marble columns}

The SEM comparison investigations of infected areas in historic marble columns with areas where no fungi are present in the same environmental conditions (Fig. 4) have shown the presence of microorganisms living inside the marble structure and confirmed the role played by microorganisms in promoting stone deterioration through a variety of mechanisms chemically, mechanically, and esthetically as mentioned above (Lamenti et al. 2000; Obuekwe et al. 2005).

\section{Characterization of the synthesized nanocoatings by TEM}

Figure 5 shows TEM micrographs of the obtained nanocomposites, to evaluate the mixture process between $\mathrm{ZnO}$ nanoparticles and Paraloid B44. The characterization by TEM showed that the nanoparticles were homogenously dispersed and interacted in the nanocomposites without aggregates of nanoparticles in polymer matrix, with the formation of $\mathrm{ZnO}$ nanoparticles/polymer nanocomposites ( $\mathrm{ZnO}$ nanoparticles marked with red circle) (Fig. 5a). Investigation size of $\mathrm{ZnO}$ nanoparticles after mixing process indicated that the nanoparticles diameter lies in the range 15 to $50 \mathrm{~nm}$ with a spherical morphology, and no aggregates were observed (Fig. 5b).

\section{Effect of nanocoating on microbial growth}

The results of treating the inoculated experimental marble samples with the polymer with or without $\mathrm{ZnO}$ nanoparticles were studied to evaluate the ability of $\mathrm{ZnO}$ nanoparticles to effect of growth of the two fungal strains $A$. niger and Penicillium sp. on marble stone surfaces. Stereo microscopy of the inoculated marble samples with A. niger and Penicillium sp. and incubated at $28^{\circ} \mathrm{C}$ for 4 weeks is shown in Figs. 6 and 7. From the results, it was clearly observed that there is a very high rate of a diffuse growth of the two fungal strains A. niger and Penicillium sp. on untreated marble specimens (Fig. 6a and b and Fig. 7a and b). This is probably due to the chemical composition of marble stone, the greater roughness of stone surface, initial porosity, and mineralogical characteristics that make stone more susceptible to microbiological attack (Karaca et al. 2015). In addition to the high ratio of calcite as a major constituent of marble stone, it is composed primarily of the mineral calcite $\left(\mathrm{CaCO}_{3}\right)$, and some other mineral impurities, such as clay minerals, quartz, pyrite, iron oxides, and graphite, which provides an appropriate environment of microbial growth (Tiano 2002; Macedo et al. 2009).

The micrographs of marble samples treated with acrylic polymer without $\mathrm{ZnO}$ nanoparticles (Fig. $6 \mathrm{c}$ and $\mathrm{d}$ and Fig. $7 \mathrm{c}$ and d) showed the growth of A. niger and Penicillium sp. in some areas on the surface, although the microbial growth seem less than untreated samples, but the results revealed that the pure polymer could not completely prevent the growth of the fungus and still the spores and hyphae could still be seen. This is due to the fact that, although the acrylic polymer plays an effective role in stabilizing historic stone structures, but as this polymer is an organic polymer, it can not only be degraded by microbial attack, but also, it could conceivably stimulate growth of some other organisms (Flemming 1998; Cappitelli and Sorlini 2008). On the other hand, the micrographs of the marble samples treated with acrylic polymer containing $\mathrm{ZnO}$ nanoparticles (Fig. 6e and f Fig. 7e and f) clearly showed that the coating induced an inhibition and prevented fungal growth, and the nanoparticles improved the efficiency of this biocidal feature. This is due to the high photocatalytic
Table 2 Identification of fungal isolates detected in infected marble samples

\begin{tabular}{llll}
\hline Serial no. & Physical observation & Fungal genera & Fungal species \\
\hline 1 & Brown spots & Aspergillus & $\begin{array}{c}\text { Aspergillus niger, Aspergillus flavus, } \\
\text { Aspergillus sydowii } \\
\text { Penicillium sp., Penicillium chrysogenum, } \\
\text { Penicillium sp. } 1\end{array}$ \\
3 & Brown spots & Penicillium & $\begin{array}{c}\text { Cladosporium sp., Cladosporium } \\
\text { herbarum }\end{array}$ \\
4 & Brown spots & Cladosporium & Ulocladium alternaria \\
Total & Black spots & Ulocladium & 9 \\
\hline
\end{tabular}



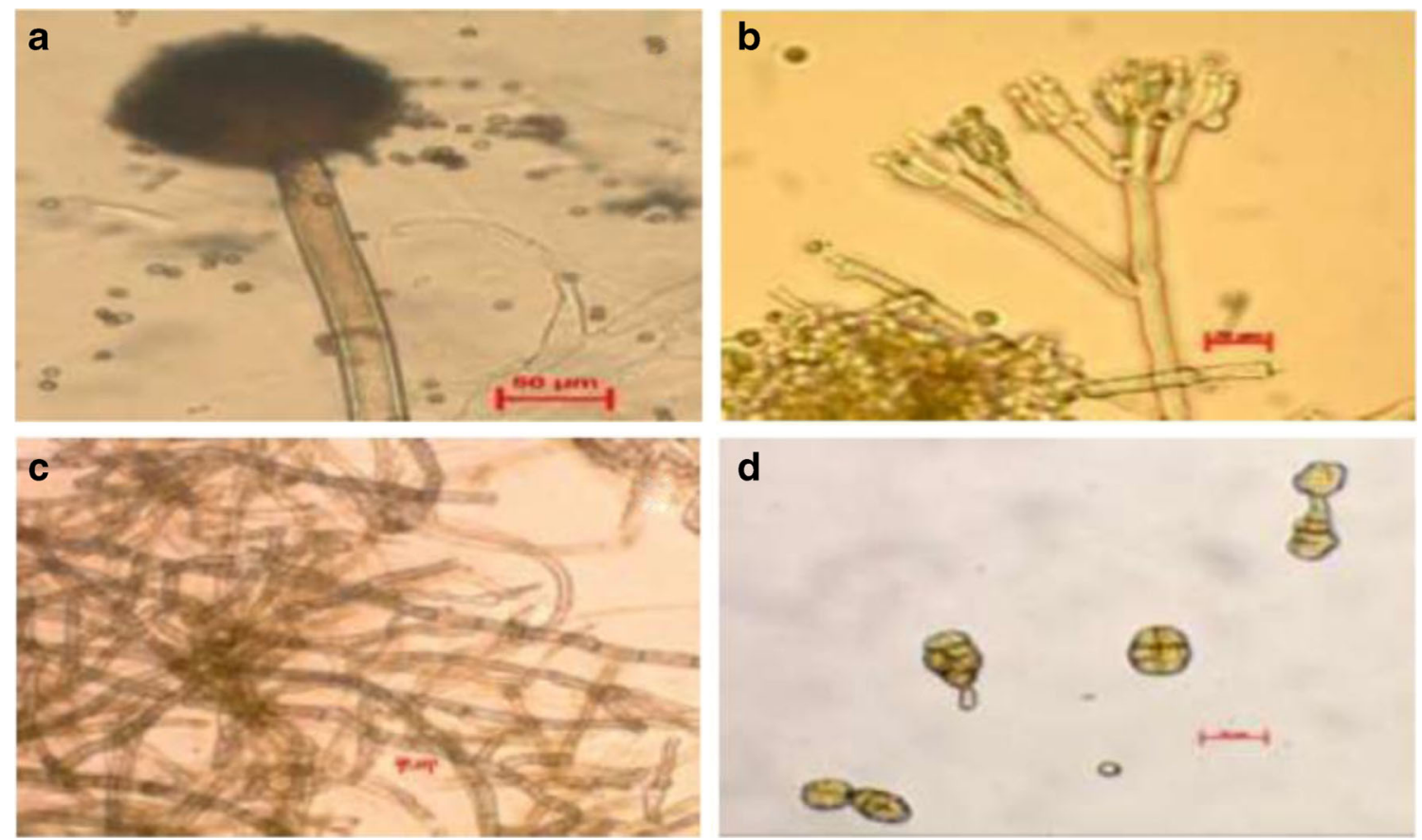

Fig. 3 Microscopic examination of isolated fungi. a Aspergillus niger, b Penicillium sp., c Cladosporium herbarum, and d Ulocladium alternaria

properties of $\mathrm{ZnO}$ as mentioned above, and the ability of $\mathrm{ZnO}$ as a semiconducting material, the band gap between conduction and valence electrons played a vital role in the generation of reactive oxygen species (ROS), which causes deterioration of microbial cell membrane.

\section{Evaluation of stone surface morphology by SEM}

SEM examination of uncoated, coated, and coated sample post thermal aging clearly showed that adding the photocatalytic $\mathrm{ZnO}$ nanoparticles to the polymer matrix plays an effective role in obtaining homogenous and compact coatings on marble surfaces. SEM micrographs of untreated marble samples (Fig. 8a) showed many voids and cracks in stone structures as a result of the disintegration of binding materials. SEM micrograph of coated samples (Fig. $8 \mathrm{~b}$ and c) revealed that the polymer containing $\mathrm{ZnO}$ nanoparticles showed a homogeneous coating of the particles and that they uniformly cover the surface without causing cracks and segregation compared to uncoated samples and the samples coated with the acrylic polymer without $\mathrm{ZnO}$ nanoparticles. After artificial thermal aging, some changes were observed in samples
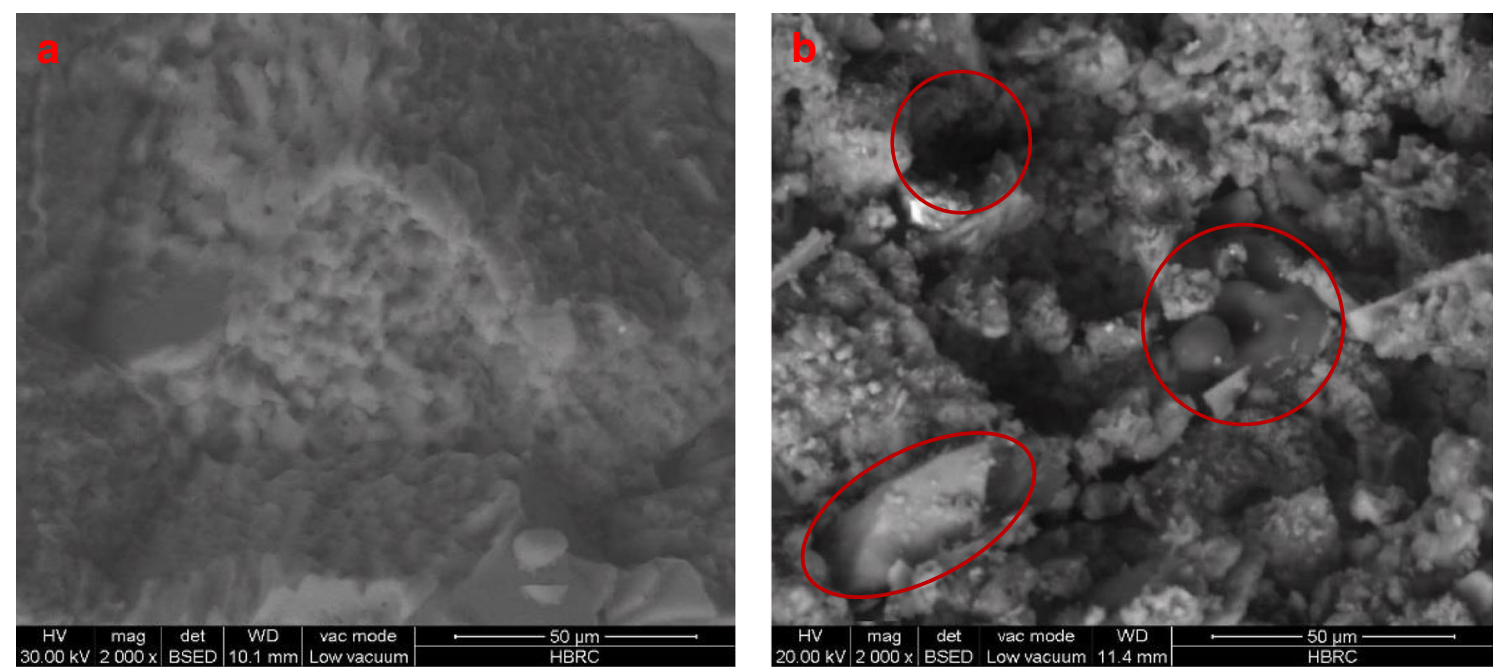

Fig. 4 SEM micrographs show the comparison between infected and uninfected marble samples. a Uninfected historic marble sample and $\mathbf{b}$ the microbial infected historic marble sample showing how mechanical properties of stone are affected due to microbial infection 

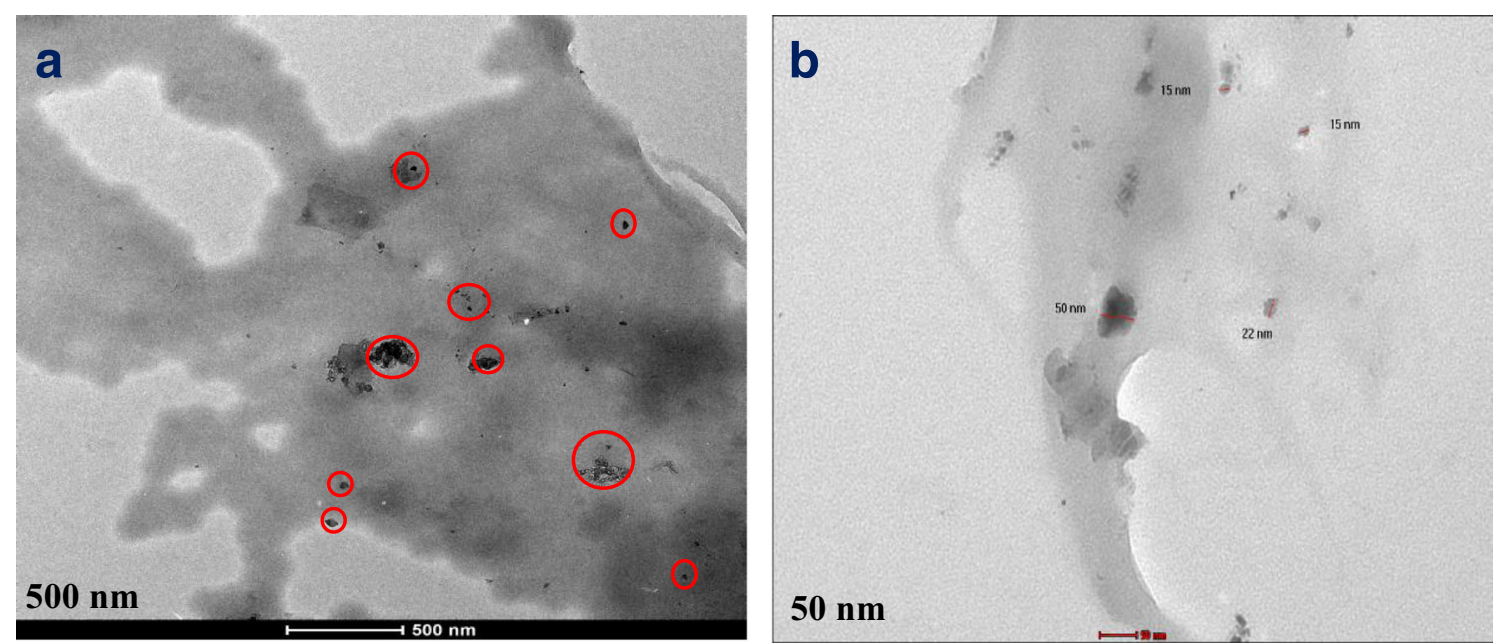

Fig. 5 TEM micrographs of the prepared $\mathrm{ZnO}$ nanoparticles/polymer nanocomposites after synthesis process: a showing the homogeneous dispersion between $\mathrm{ZnO}$ nanoparticles and Paraloid B44 and $\mathbf{b}$ showing $\mathrm{ZnO}$ particle size and spherical morphology

Fig. 6 Stereo microscopy of fungal colonization growth on experimental marble samples after 4 weeks since inoculation by A. niger fungi; $\mathbf{a}, \mathbf{b}$ Untreated marble samples; $\mathbf{c}, \mathbf{d}$

Experimental samples treated with synthesized B44; e, f

Samples treated with synthesized $\mathrm{ZnO}$ /polymer nanocomposites
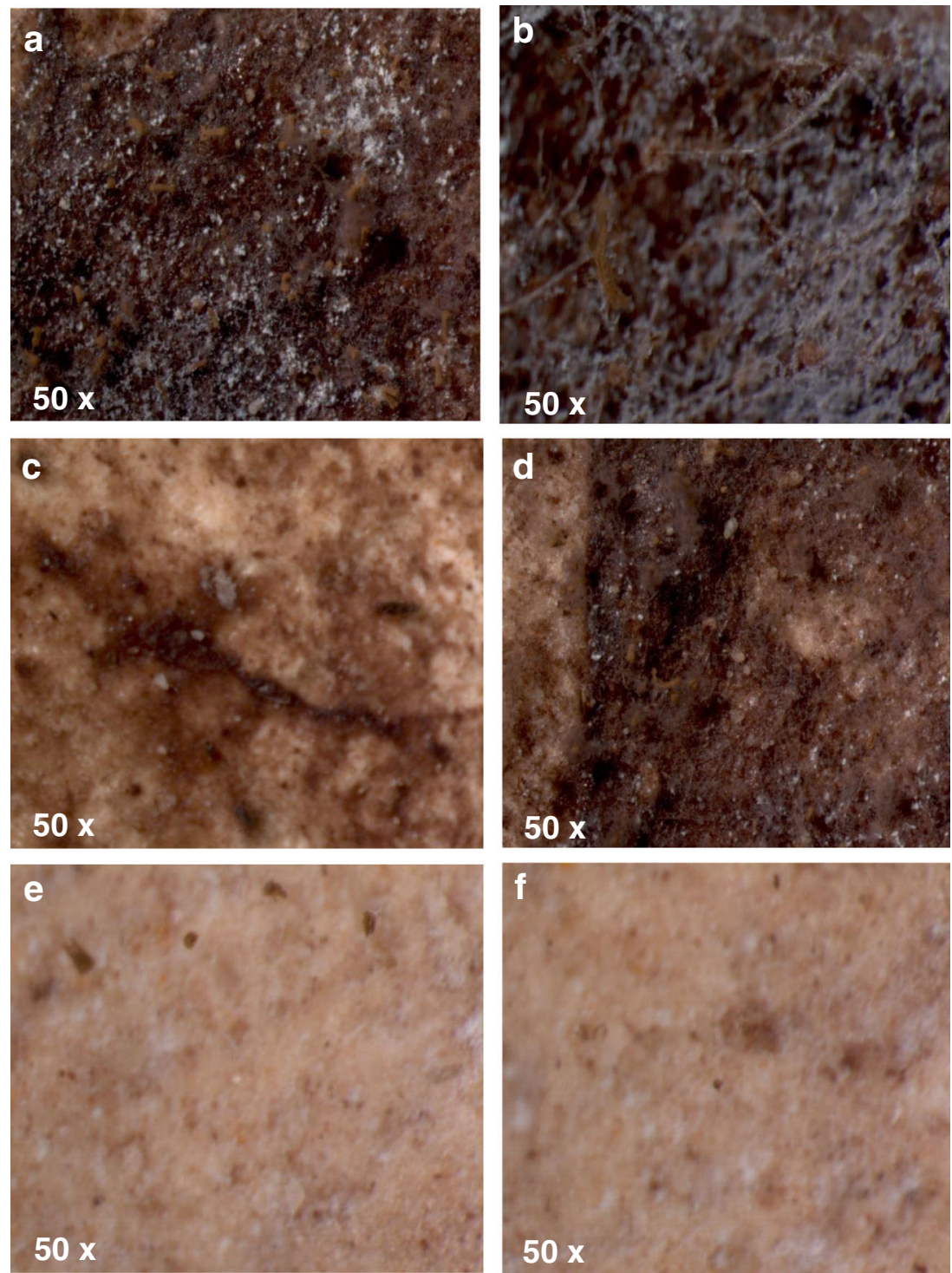
Fig. 7 Stereo microscopy of fungal colonization growth on experimental marble samples after 4 weeks since inoculation by Penicillium sp. fungi; a, b Untreated marble samples; $\mathbf{c}, \mathbf{d}$ Experimental samples treated with synthesized B44; $\mathbf{e}, \mathbf{f}$ Samples treated with synthesized $\mathrm{ZnO}$ /polymer nanocomposites
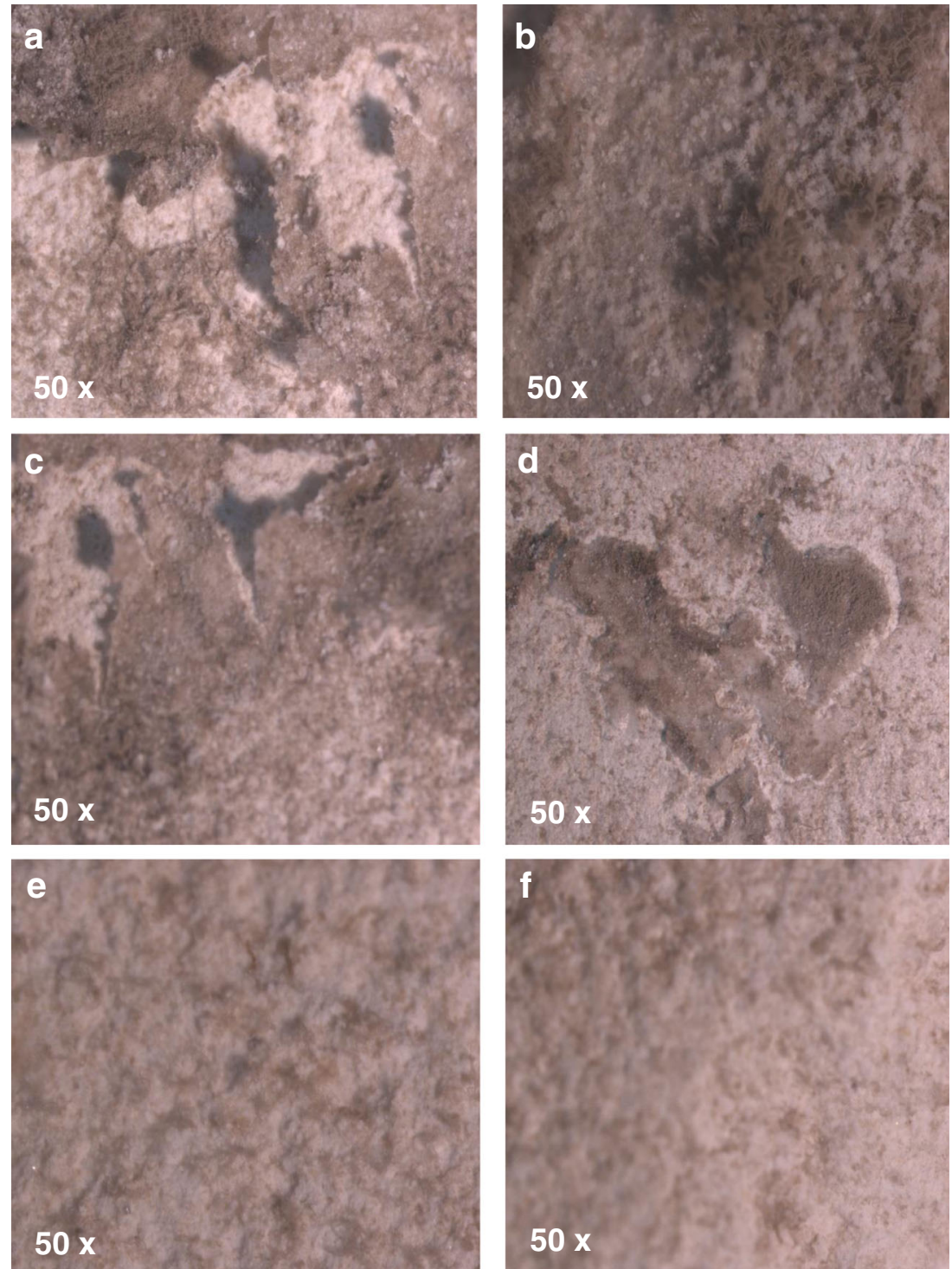

treated with both products; SEM micrograph of the samples coated with pure polymer without nanoparticles (Fig. 8d) was found to be dried and the temperature affected on the film homogeneity due to solvent removal and subsequent decrease of the film free volume; showing cracks of the resins. On the other hand, in the samples coated with Paraloid B-44 containing $\mathrm{ZnO}$ nanoparticles (Fig. 8e), small fine cracks were observed in the coating film in some areas, but without any side effects on the film uniform and homogeneity, no further influence observed on the coating properties of the remedy compared to those coated with Paraloid B-44 without the nanoparticles. The nanoparticles enhanced the durability of the coating to be stable under the effect of the artificial thermal aging. And, due to the very low porosity (less than 1\%) of both nanocoatings, they do not easily penetrate in the crystalline porous structure. $\mathrm{ZnO} /$ polymer nanocomposites show a slightly better penetration in this substrate.

\section{Fourier-transformed infrared (ATR-FTIR) spectroscopy}

The infrared spectrum of the sample treated with pure Paraloid B-44 before artificial aging showed the presence of multiple bands in asymmetric and symmetric $\mathrm{C}-\mathrm{H}$ stretching region between 3061 and $2872 \mathrm{~cm}^{-1}$ and in $\mathrm{C}-\mathrm{O}$ stretching region between 1158 and $1028 \mathrm{~cm}^{-1}$ in addition to $\mathrm{C}=\mathrm{O}$ stretching band at $1727 \mathrm{~cm}^{-1}$ which corresponds to the main functional group of B-44.

After thermal aging, the spectrum showed that the intensity of $\mathrm{C}=\mathrm{O}$ stretching band at $1727 \mathrm{~cm}^{-1}$ sharply decreased. While, all the absorption bands in $\mathrm{C}-\mathrm{O}$ stretching region and $\mathrm{C}-\mathrm{H}$ stretching region vanished compared with those of the unaged treated sample. This meant that the typical absorption bands varied and the major chemical groups were affected during thermal degradation. This may be due to the loss of monomers and small fragments 

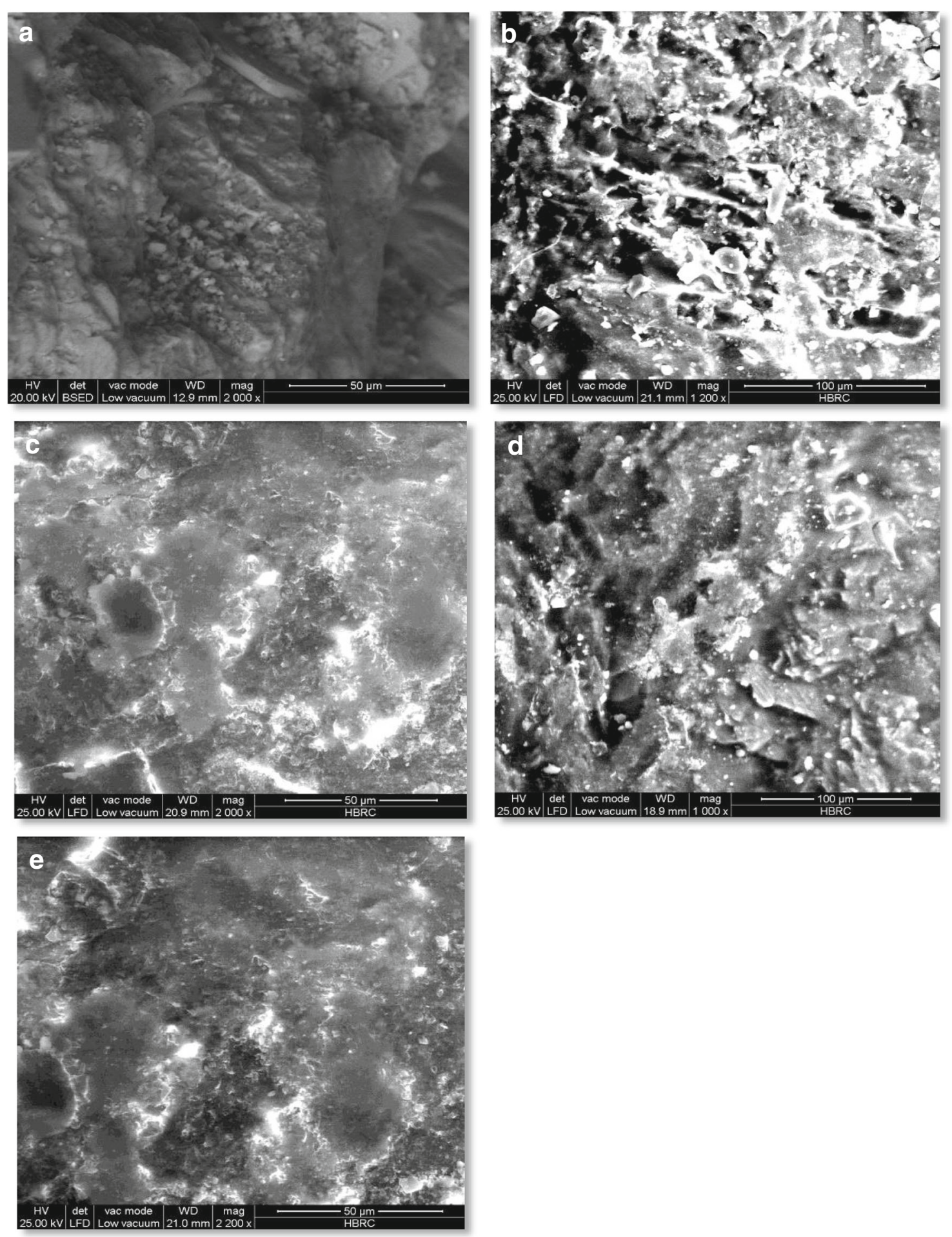

Fig. 8 SEM micrographs of the experimental marble samples. a Untreated; b coated with Paraloid B44, and $\mathbf{c}$ coated with Paraloid B44 + ZnO nanoparticles, and $\mathbf{d}$ coated with Paraloid B44 after thermal aging, and $\mathbf{e}$ coated with Paraloid B44 + ZnO nanoparticles after thermal aging

formed as a result of the chain scissions. Moreover, no oxygen-containing functional groups were formed indicating the good stability of B-44 towards thermal oxidation. These conclusions are in tandem with those obtained by Lazzari and Chiantore, who concluded that in both acrylic and methacrylic resins where all or the majority of the alkyl side groups are short, chain scissions prevail over cross-linking and the resins showed good stability towards oxidation (Lazzari and Chiantore 2000; Chiantore and Lazzari 2001). 


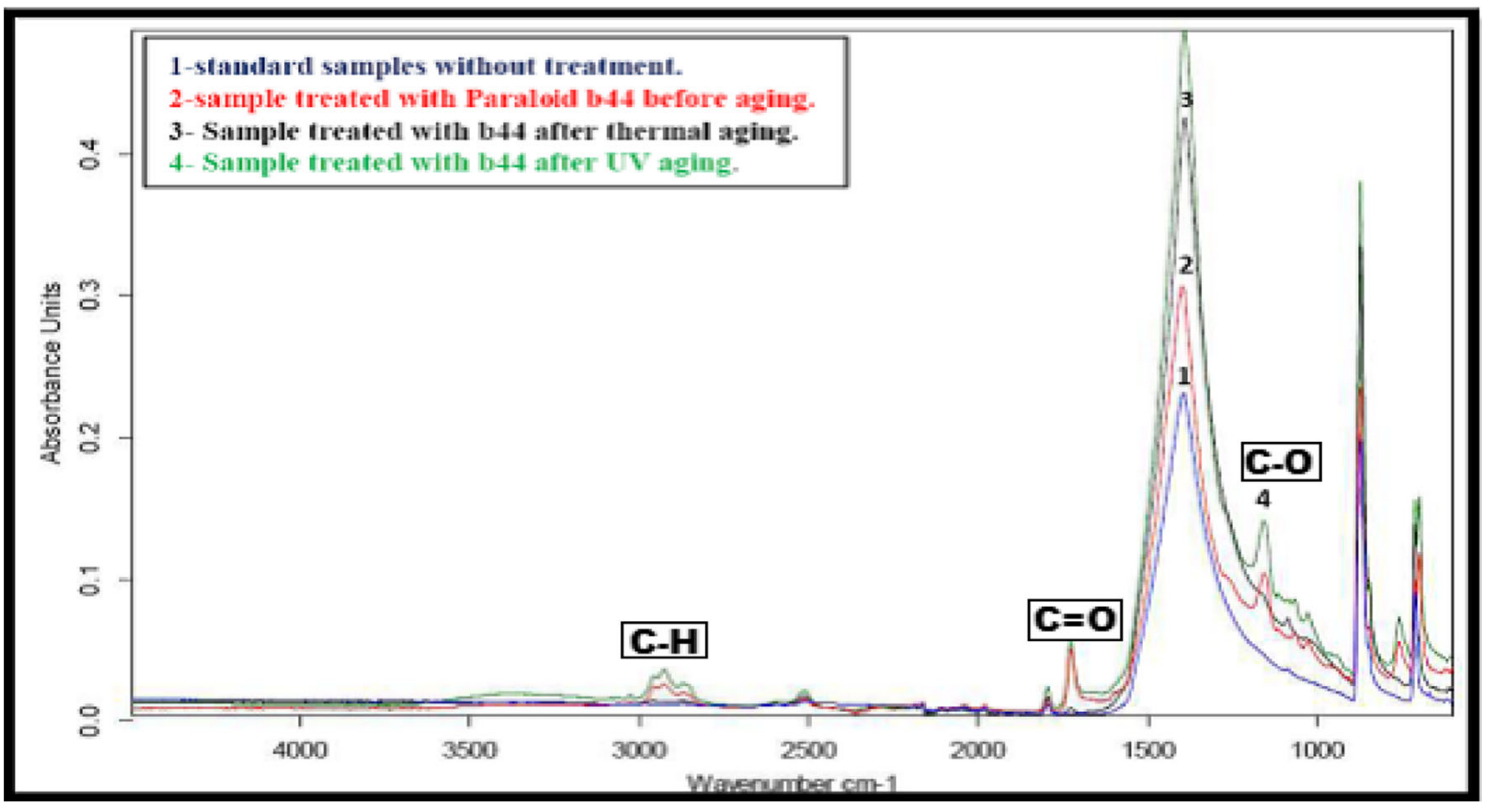

Fig. 9 FTIR-ATR spectra of the sample treated with Paraloid B-44. (1) Untreated surface; (2) treated surface before aging; (3) surface after thermal aging; (4) surface after UV aging

On the other hand, UV aging showed slight variations in all the absorption bands representing B-44. The same results were obtained by Chiantore and Lazzari, who found that the resins containing only ethyl and methyl esters displayed a good stability towards oxidation, reaching an equilibrium between scission reactions and macromolecular coupling which permit them to maintain their molecular characteristics during artificial light aging. The changes that happened at the main absorption peaks of B-44 during thermal and UV aging are shown in (Fig. 9).

The infrared spectra of the samples treated with the $\mathrm{ZnO}$ nanoparticles/polymer nanocomposites before and after artificial thermal aging (Fig. 10) showed slight variations in the main absorption bands of B-44 suggesting the stability of

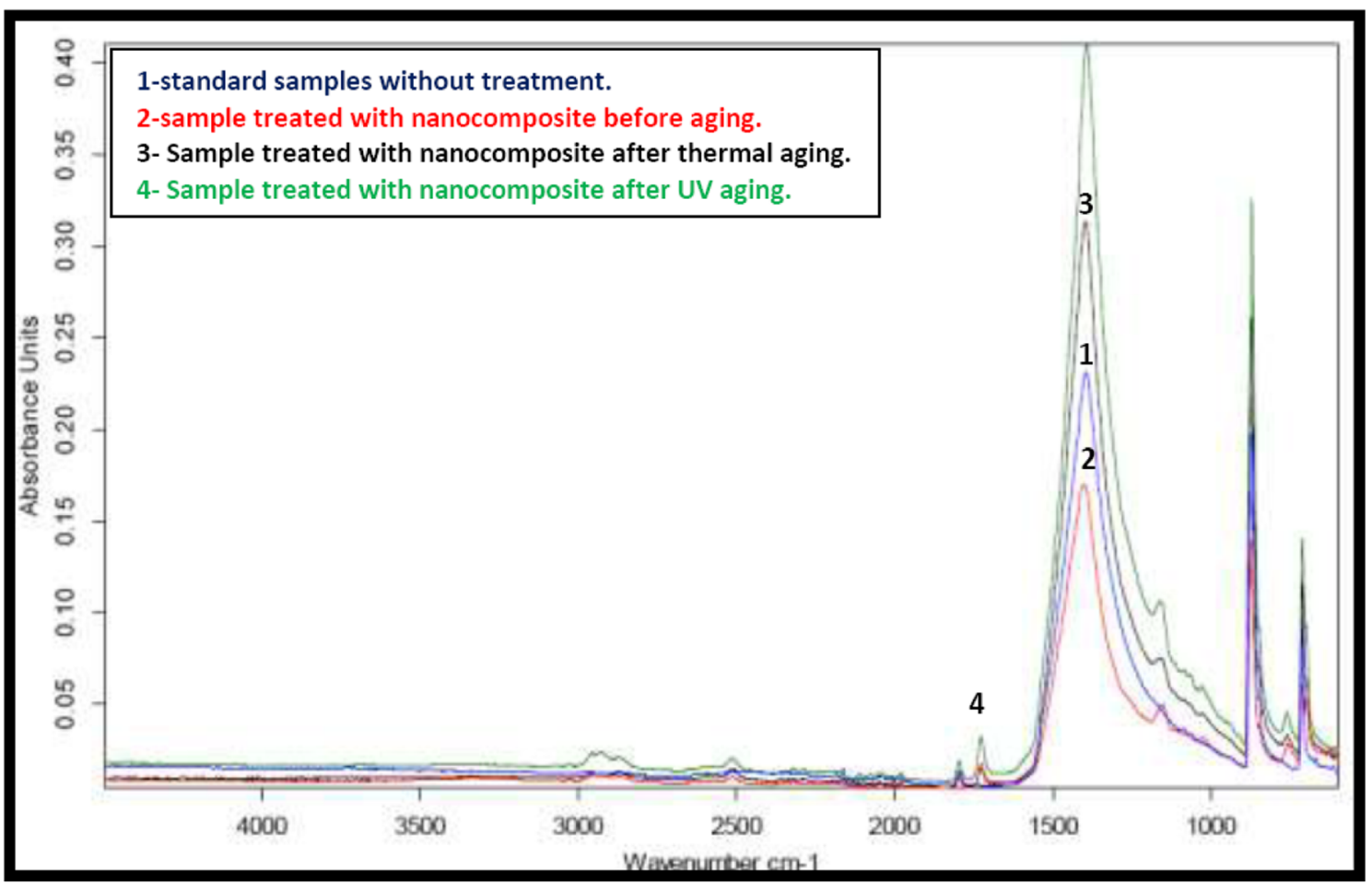

Fig. 10 FTIR-ATR spectra of the sample treated with $\mathrm{ZnO}$ nanoparticles/polymer nanocomposites. (1) Untreated surface; (2) treated surface before aging; (3) surface after thermal aging; (4) surface after UV aging 
Table 3 Color measurements on untreated, treated, and aged samples

\begin{tabular}{|c|c|c|c|c|c|c|c|c|c|c|c|c|}
\hline \multirow[t]{2}{*}{ Applied protective materials } & \multicolumn{4}{|c|}{$\Delta$ (treated and untreated samples) } & \multicolumn{4}{|c|}{$\Delta$ (UV aged and untreated samples) } & \multicolumn{4}{|c|}{$\Delta$ (thermal aged and untreated samples) } \\
\hline & $\Delta L^{*}$ & $\Delta a^{*}$ & $\Delta b^{*}$ & $\Delta E$ & $\Delta L^{*}$ & $\Delta a^{*}$ & $\Delta b^{*}$ & $\Delta E$ & $\Delta L^{*}$ & $\Delta a^{*}$ & $\Delta b^{*}$ & $\Delta E$ \\
\hline Paraloid B44 & 0.86 & 0.09 & 0.47 & 0.98 & 0.63 & 0.53 & 2.30 & 2.44 & 2.06 & 0.61 & 2.97 & 3.67 \\
\hline $\begin{array}{l}\mathrm{ZnO} \text { nanoparticles/polymer } \\
\text { nanocomposites }\end{array}$ & 0.11 & 0.28 & 0.34 & 0.45 & -1.56 & -0.48 & 1.77 & 2.41 & -2.17 & 0.40 & 1.36 & 2.59 \\
\hline
\end{tabular}

the corresponding functional groups during thermal aging process compared with those of the samples treated with acrylic polymer without $\mathrm{ZnO}$ nanoparticles. No remarkable changes were observed in bands intensities of the sample treated with the $\mathrm{ZnO}$ nanoparticles/polymer nanocomposites after exposure to UV radiations, suggesting the success of $\mathrm{ZnO}$ nanoparticles in enhancing the physical and mechanical properties of acrylic polymers.

In general, the $\mathrm{ZnO}$ nanoparticles/polymer nanocomposites showed good stability towards the UV aging compared to the pure B-44. Also, the treatment with $\mathrm{ZnO}$ nanoparticles/ polymer nanocomposites appears to be better than that with pure B-44 towards the thermal aging. This is attributed to not only the high chemical and physicomechanical properties of nanoparticles which play an effective role in increasing the hydrophobic character of the polymer, but also due to the superior properties of Paraloid B-44 which forms a hard coating, that is extremely stable to degradation by heat and oxidation, even though there were small effects in bands intensities, but better than that of the samples treated with pure B- 44 only.

\section{Colorimetric measurements}

As esthetics and historic values are very important issues in conservation science, the color variations were recorded before, after coating and after aging in order to preserve the original color of surfaces. Color alterations are expressed by the $\Delta \mathrm{E}$ parameter, which indicates the difference between each chromatic coordinate $\left(\Delta \mathrm{L}^{*}, \Delta \mathrm{a}^{*}\right.$, and $\left.\Delta \mathrm{b}^{*}\right)$ in uncoated, coated, and coated aged samples.

Table 4 Values of static water contact angle $\theta\left(^{\circ}\right)$ for uncoated and coated marble samples

\begin{tabular}{lll}
\hline Samples & $\begin{array}{l}\text { Contact angle measurement } \\
\text { for uncoated and coated samples } \\
\theta\left( \pm 3^{\circ}\right)\end{array}$ & $\begin{array}{c}\text { Standard } \\
\text { deviation }\end{array}$ \\
\hline Uncoated samples & $112^{\circ}$ & 1.24 \\
$\begin{array}{l}\text { Samples coated with } \\
\quad \text { Paraloid B44 }\end{array}$ & $125^{\circ}$ & 0.82 \\
$\begin{array}{l}\text { Samples coated with } \\
\text { ZnO/polymer } \\
\text { nanocomposites }\end{array}$ & $140^{\circ}$ & 0.47 \\
\hline
\end{tabular}

The color modification $(\Delta \mathrm{E})$ was calculated using the following relation:

$\Delta \mathrm{E}^{*}=\left[\left(\mathrm{L}_{2} *-\mathrm{L}_{1} *\right)^{2}+\left(\mathrm{a}_{2} *-\mathrm{a}_{1} *\right)^{2}+\left(\mathrm{b}_{2} *-\mathrm{b}_{1} *\right)^{2}\right]^{1 / 2}$.

where $\Delta \mathrm{L}^{*}, \Delta \mathrm{a}^{*}$, and $\Delta \mathrm{b}^{*}$ represent the difference between the value of each chromatic coordinate in treated samples and the value in untreated ones. According to Italian guidelines for the restoration of stone monuments, the $\Delta \mathrm{E}$ value must be $<5$ (Normal $-43 / 93$. 1993). The results of $\Delta \mathrm{E}$ values were recorded after coating application and artificial U. V and thermal aging, samples treated with Paraloid B44 have $\Delta \mathrm{E}$ values between $0.98,2.44$, and 3.67 , but those treated with $\mathrm{ZnO}$ nanoparticles/polymer nanocomposites have $\Delta \mathrm{E}$ values between $0.45,2.41$, and 2.59 , it is notified that after treatment and aging, negligible color variations were observed, and all values in the acceptable limit $(\Delta \mathrm{E}$ value $<5)$ thus confirming the suitability of the product for conservation purposes. Nevertheless, it is notified that the $\Delta \mathrm{E}$ values of samples treated with nanocomposites are still more acceptable than those treated with Paraloid B44 without $\mathrm{ZnO}$ nanoparticles since they are near to 5 . The completed data is listed in (Table 3).

\section{Measurements of water contact angle}

The equilibrium water contact angle measurements $(\theta)$ for uncoated and coated samples were calculated as a reference point. The aim is to characterize the behavior of photoactive nanoparticle in terms of water resistance and decrease in wettability. The " $\theta$ " measurement is an average rate by measurements on three drops (UNI 11207. 2007). The results in Table 4 and Fig. 11 showed that the coating containing $\mathrm{ZnO}$ nanoparticles achieved the best results in the test of hydrophobicity compared to uncoated samples or those coated with Pure Paraloid B-44. The hydrophobic action mainly attributes to the polymer not nanoparticles; although, the nanoparticles help in increasing the hydrophobic character of the coating and also play an effective role in enhancing the polymer with self-protection properties which are a very important aim to prevent further microbial deterioration. But the highest hydrophobic action depends on the chemical and physical properties of the polymer and the nanoscale roughness of the surface that 

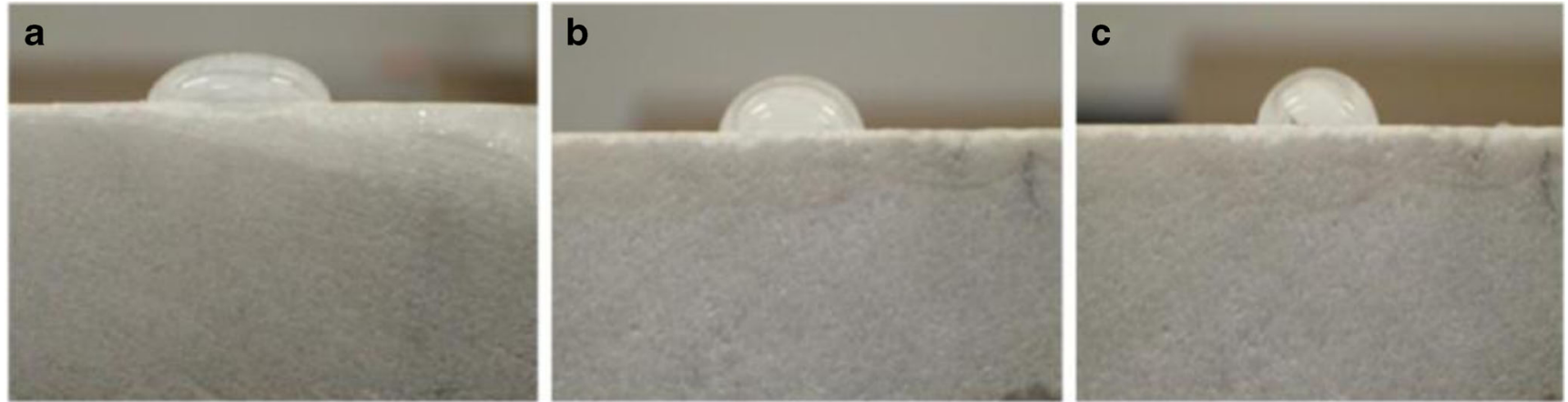

Fig. 11 Drops of distilled water on the surface of the experimental marble samples for static contact angle measurement. a Uncoated sample, $\mathbf{b}$ sample coated with pure Paraloid B44, and $\mathbf{c}$ sample coated with $\mathrm{ZnO}$ nanoparticles/polymer nanocomposites

leads to the trapping of air between the water droplet and the rough surface. Moreover, the very low porosity of marble stone helps to make the surface naturally more hydrophobic.

\section{Evaluation of capillary water absorption}

Water plays an effective role in the chemical and microbiological deterioration processes of stone monuments; therefore, conservators will always seek to apply coatings and consolidation materials with hydrophobic properties that are able to reduce water penetration into the stone bulk. From the results, good water repellency was observed in the samples after treatment by pure $\mathrm{B} 44$ and after adding the $\mathrm{ZnO}$ nanoparticles. In particular, the coating with $\mathrm{ZnO}$ nanoparticles reveals much better results. Analyses were carried out on both untreated and freshly treated samples as well as after artificial aging. After UV irradiation, samples coated with pure B44 and blends containing zinc nanoparticles preserve good water repellency, even where there were slight variations observed, but treated surfaces seem to be unaffected by solar radiation, with no significant difference found between the two different amounts of product. After artificial thermal aging, the behavior was slightly different; there is the effect of the polymer degradation that can lead to small alteration of the original features, especially in the case of pure B44, thus revealing a loss of the hydrophobic features of protective coatings, but we can note that the decrease of hydrophobic performance has been revealed in the case of pure acrylic polymer more than polymer containing $\mathrm{ZnO}$ nanoparticles. Furthermore, the low porosity of marble stone plays a major role in the water absorption process, so the coating materials cannot penetrate deeply in the stone bulk. Complete data are listed in Table 5.

\section{Conclusion}

In this study, the photocatalyst metal oxide $\mathrm{ZnO}$ nanoparticles were dispersed in synthesized acrylic polymer (Paraloid B44) to obtain a new nanocoating with effective biocidal, self-protection, and hydrophobic features, to be used in the protection of deteriorated exposed marble columns at historic sites. TEM images showed that $\mathrm{ZnO}$ /polymer nanocomposites were successfully prepared by emulsion polymerization. Moreover, the biocidal effectiveness of the $\mathrm{ZnO}$ nanoparticles against Penicillium sp. and Aspergillus niger were also assessed; a diffuse growth of colonies was observed on untreated specimens and on those treated with pure polymer, while growth inhibition was observed on coatings containing $\mathrm{ZnO}$ nanoparticles, suggesting that these have effective biocidal properties. Self-protection, consolidation, and hydrophobic features of the nanocoating have been performed before, after coating, and after artificial UV and thermal aging. The results have shown that coatings containing $\mathrm{ZnO}$ nanoparticles induce a remarkable increase of contact angle and water capillary absorption. Coatings containing $\mathrm{ZnO}$ enhanced the durability of stone surfaces against UV aging and improved their resistance to RH and temperature fluctuations in comparison with samples coated with only acrylic polymer. Fungal inhibition and

Table 5 Physical properties of coated and coated aged samples

\begin{tabular}{|c|c|c|c|c|c|c|c|c|c|}
\hline \multirow[t]{2}{*}{ Applied protective materials } & \multicolumn{3}{|c|}{ After coating } & \multicolumn{3}{|c|}{ After UV aging } & \multicolumn{3}{|c|}{ After thermal aging } \\
\hline & $\begin{array}{l}\text { Density } \\
\mathrm{gm} / \mathrm{cm}^{3}\end{array}$ & Porosity $\%$ & $\begin{array}{l}\text { Water } \\
\text { absorption \% }\end{array}$ & $\begin{array}{l}\text { Density } \\
\mathrm{gm} / \mathrm{cm}^{3}\end{array}$ & Porosity \% & $\begin{array}{l}\text { Water absorption } \\
\%\end{array}$ & $\begin{array}{l}\text { Density } \\
\mathrm{gm} / \mathrm{cm}^{3}\end{array}$ & Porosity $\%$ & $\begin{array}{l}\text { Water absorption } \\
\%\end{array}$ \\
\hline Paraloid B44 & 2.84 & $0.19 \%$ & $0.08 \%$ & 2.81 & 0.19 & 0.09 & 2.75 & 0.21 & 0.101 \\
\hline $\begin{array}{l}\mathrm{ZnO} \text { nanoparticles/polymer } \\
\text { nanocomposites }\end{array}$ & 2.87 & $0.13 \%$ & $0.05 \%$ & 2.85 & 0.14 & 0.05 & 2.82 & 0.16 & 0.071 \\
\hline
\end{tabular}


self-protection properties were confirmed without any observed color change on the surface. In terms of multifunctional features, $\mathrm{ZnO}$ nanocoating is particularly suitable as a surface coating for historic marble stones, with protective properties. This work presented a novel study about improvement of coating materials to obtain a long-term protection of deteriorated historic marble columns at historic sites. The study confirmed the success of the preparation method of nanocomposites by in situ emulsion polymerization and the possibility for the application in conservation of stone monuments.

Acknowledgments The authors would like to express their gratitude sincere to King Abdulalziz City for Science and Technology (KACST), Riyadh, Saudi Arabia for the valuable and continuous scientific and moral support. The authors acknowledge the valuable assistance given by Rosamond Artis, Director of Scottish Lime Center Trust, UK.

Author contributions Sawsan S. Darwish, Sayed M. Ahmed, and Mohammad A. Aldosari conceived and designed the experiments; Sayed M. Ahmed and Mahmoud A. Adam performed the experiments; Sawsan S. Darwish, Nagib A. Elmarzugi, and Mahmoud A. Adam analyzed the data; Mohamed A. Aldosari and Nagib A. Elmarzugi contributed reagents/materials/analysis tools; Sawsan S. Darwish and Sayed M. Ahmed wrote the paper.

\section{Compliance with ethical standards}

Conflicts of interest The authors declare that they have no conflicts of interest.

Open Access This article is distributed under the terms of the Creative Commons Attribution 4.0 International License (http:// creativecommons.org/licenses/by/4.0/), which permits unrestricted use, distribution, and reproduction in any medium, provided you give appropriate credit to the original author(s) and the source, provide a link to the Creative Commons license, and indicate if changes were made.

Publisher's Note Springer Nature remains neutral with regard to jurisdictional claims in published maps and institutional affiliations.

\section{References}

Abdelhafez MAA, El-Wekeel FM, Ramadan EM, Abed-Allah AA (2012) Microbial deterioration of archaeological marble: identification and treatment. Ann Agric Sci 57(2):137-144

Aldosari MA, Darwish SS, Adam MA, Elmarzugi NA, Ahmed SM (2017a) Protecting of marble stone facades of historic buildings using multifunctional $\mathrm{TiO}_{2}$ nanocoatings. Sustainability 9, 2002:115. https://doi.org/10.3390/su9112002

Aldosari MA, Darwish SS, Adam MA, Elmarzugi NA, Ahmed SM (2017b) Enhancing the durability of calcareous stone monuments of ancient Egypt using $\mathrm{CaCO} 3$ nanoparticles. Sustainability 9, 1392: 1-17. https://doi.org/10.3390/su9081392

Bakr AM (2011) Evaluation of the reliability and durability of some chemical treatments proposed for consolidation of so called- marble decoration used in 19th century cemetery (Hosh Al Basha), Cairo, Egypt. J Arab Archaeol Union 12:75-96

Bracci S, Melo MJ (2003) Correlating nature ageing and Xenon irradiation of Paraloid B72 applied on stone. Polym Degrad Stab 80(3):533-541

Cappitelli F, Sorlini C (2008) Microorganisms attack synthetic polymers in items representing our cultural heritage. Appl Environ Microbiol 74(3):564-569

Chiantore O, Lazzari M (2001) Photo-oxidative stability of paraloid acrylic protective polymers. Polymer 42:17-27

CIE Standard (2007). The International Organization for Standardization (ISO). CIE Standard S014-4/E, Colorimetry. Part 4: CIE 1976 $\mathrm{L} * a * b *$ Colour Space; ISO: Genève, Switzerland

Cioffi N, Torsi L, Ditaranto N, Sabbatini L, Zambonin PG (2004) Antifungal activity of polymer-based copper nanocomposite coatings. Appl Phys Lett 85:2417-2419

Cioffi N, Torsi L, Ditaranto N, Tantillo G, Ghibelli L, Sabbatini L, BleveZacheo T, D'Alessio M, Zambonin PG, Traversa E (2005) Copper nanoparticle/polymer composites with antifungal and bacteriostatic properties. Chem Mater 17:5255-5262

Cooke WB (1963) A laboratory guide to fungi in polluted waters, sewage, and sewage treatment systems; their identification and culture. U.S.Dept.of Health, Education and welfare, Public Health Service, Cincinnati, Ohio

Diakumaku E, Ausset P, Sterflinger K, Wollenzien U, Lefevre RA (1994) On the problem of rock blackening by fly ash, fungal and other biogenic particles and their detection in Mediterranean marbles and monuments. La conservazione dei monumenti nel bacino del Mediterraneo: atti del $3^{\circ}$ simposio internazionale, Venezia, 22-25 giugno, Italy, pp 305-310

Ditaranto N, Loperfido S, Van der Werf I, Mangone A, Nicola C, Sabbatini L (2011) Synthesis and analytical characterisation of copper-based nanocoatings for bioactive stone artworks treatment. Anal Bioanal Chem 399:473-481

Ditaranto N, van der Werf I, Picca RA, Sportelli MC, Giannossa LC, Bonerba E, Tantillo G, Sabbatini L (2015) Characterization and behaviour of $\mathrm{ZnO}$-based nanocomposites designed for the control of biodeterioration of patrimonial stoneworks. New J Chem 68366843. https://doi.org/10.1039/C5NJ00527B

Domsch KH, Gams W, Anderson TH (2008) In: compendium of soil Fungi. Eur J Soil Sci 59:1007-1011

Dutta RK, Nenavathu BP, Gangishetty MK, Reddy AVR (2012) Studies on antibacterial activity of $\mathrm{ZnO}$ nanoparticles by ROS induced lipid peroxidation. Colloids Surf B Biointerfaces 94:143-150

Espitia PJP, Soares NDF, Coimbra JSD, Andrade NJ, Cruz RS, Medeiros EA (2012) Zinc oxide nanoparticles: synthesis, antimicrobial activity and food packaging applications. Food Bioprocess Technol 5:1447-1464

Farooq M, Hassan M, Gull F (2015) Mycobial deterioration of stone monuments of Dharmarajika. Taxila J Microbiol Exp 2(1):2-6

Feng L, Leonardo SC (2006) Preparation and characterization of polymer $\mathrm{TiO}_{2}$ hybrid nanocomposites via in situ polymerization. Master's thesis. University of Waterloo, Waterloo, pp 77-80

Flemming HC (1998) Relevance of biofilms for the biodeterioration of surfaces of polymeric materials. Polym Degrad Stabil 59:309-315

Frank-Kamenetskaya O, Vlasov D, Shilova OA (2010) Biogenic crystals genesis on a carbonate rock monuments surface: the main factors and mechanisms, development of nanotechnology ways of inhibition. RMS DPI 2:16-11

Gilman JC (1974) Manual of soil fungi. Indian Edition published by arrangement with the original American publishers Iowa State University press, USA, pp 217-251

Golego N, Studenikin SA, Cocivera M (2000) Sensor photoresponse of thin-film oxides of zinc and titanium to oxygen gas. J Electrochem Soc 147:1592-1594 
Gomez-Ortez N, De la Rosa-Garcia S, Gonzalez-Gomez W, Soria-Castro M, Quintana P, Oskam G, Ortega-Morales B (2013) Antifungal coatings based on $\mathrm{Ca}(\mathrm{OH})_{2}$ mixed with $\mathrm{ZnO} / \mathrm{TiO}_{2}$ nanomaterials for protection of limestone monuments. ACS Appl Mater Interfaces 5:1556-1565

Gorbushina AA, Krumbein WE, Hamman CH, Panina LK, Soukharjevski S, Wollenzien U (1993) Role of black fungi in colour change and biodeterioration of antique marbles. Geomicrobiol J 11:205-221

He L, Liu Y, Mustapha A, Lin M (2011) Antifungal activity of zinc oxide nanoparticles against Botrytis cinerea and Penicillium expansum. Microbiol Res 166:207-215

Helmi, F.M, Hefni, Y. A (2014) Simple method for measuring the static water contact angle for evaluation the hydrophobicity of the consolidating and protective materials. In Proceedings of the First International Conference of Egypt and Mediterranean Countries through Ages, Cairo, Egypt, 15-18 October, Volume 3, pp 327-341

Jayaseelan C, Rahuman AA, Kirthi AV, Marimuthu S, Santhoshkumar T, Bagavan A, Gaurav K, Karthik L, Rao KV (2012) Novel microbial route to synthesize $\mathrm{ZnO}$ nanoparticles using Aeromonas hydrophila and their activity against pathogenic bacteria and fungi. Spectrochim Acta Part A 90:78-84

Johnson BW, Mclntyre R (1996) Analysis of test methods for UV durability predictions of polymer coating. Prog Org Coat 27:95-106

Kapridaki C, Maravelaki-Kalaitzaki P (2013) $\mathrm{TiO}_{2}-\mathrm{SiO}_{2}-\mathrm{PDMS}$ nanocomposite hydrophobic coating with self-cleaning properties for marble protection. Progress Org Coat 76:400-410

Karaca Z, Öztürk A, Çolak E (2015) Biofouling of marbles by oxygenic photosynthetic microorganisms. Environ Sci Pollut Res 22:1-6

La Russa MF, Ruffolo SA, Rovella N, Belfiore CM, Palermo AM, Guzzi MT, Crisci GM (2012) Multifunctional $\mathrm{TiO}_{2}$ coatings for cultural heritage. Prog Org Coat 74:186-191

Lamenti G, Tiano P, Tomaselli L (2000) Biodeterioration of ornamental marble statues in the Boboli Gardens (Florence, Italy). J Appl Psychol 12(3-5):427-433

Lazzari M, Chiantore O (2000) Thermal-ageing of paraloid acrylic protective polymers. J Polymer 41:6447-6455

Licciulli A, Calia A, Lettieri M, Diso D, Masieri M, Franza S, Amadelli $\mathrm{R}$, Casarano $\mathrm{G}$ (2011) Photocatalytic $\mathrm{TiO}_{2}$ coatings on limestone. J Sol-Gel Sci Technol 60:437-444

Lipovsky A, Nitzan Y, Gedanken A, Lubart R (2011) Antifungal activity of $\mathrm{ZnO}$ nanoparticles-the role of ROS mediated cell injury. Nanotechnology 22:105101

Lopez EF, Gomez EF (1996) Simultaneous determination of the major organic acids, sugars, glycol and ethanol by HPLC in Grape musts and white wines. J Chromatogr Sci 34(5):254-257

Macedo MF, Miller AZ, Dionísio A, Saiz-Jimenez C (2009) Biodiversity of cyanobacteria and green algae on monuments in the Mediterranean Basin. Microbiology 155(11):3476-3490

Malagodi M, Nugari MP, Altieri A, Lonati G (2000) Effects of combined application of biocides and protective on marble. In: Fassina V (ed) Proceedings of the Ninth International Congress on Deterioration and Conservation of Stone, vol 2. Elsevier, Amsterdam, pp 225-233

Malešič J, Kolar J, Strlič M, Kocar D, Fromageot D, Lemaire J, Haillant O (2005) Photo-induced degradation of cellulose. Polym Degrad Stability 89:64-69

Matysik S, Herbarth O, Mueller A (2008) Determination of volatile metabolites originating from mould growth on wall paper and synthetic media. J Microbiol Methods 75:182-187

McNeill IC (1992) Fundamental aspects of polymer degradation. In: Conservation i, Allen NS, Edge M, Horie CV (eds) Polymers. Royal Society of Chemistry, Cambridge, pp 14-31

Moafi HF, Shojaie AF, Zanjanchi MA (2011) Photocatalytic self-cleaning properties of cellulosic fibers modified by nano-sized zinc oxide. Thin Solid Films 519:3641-3646
Mohamed WS, Effenberger F, Schweizer M (2009) Synthesis and characterization of some polyacrylate/montomorillite nanocomposites by in situ emulsion polymerization using redox initiation system. J Appl Polym 112:1-7

Monte M (2003) Oxalate film formation on marble specimen caused by fungus. J Cult Herit 4(3):255-258

Monteiro RD, Group FL, Takamiya SA, Ruvollo-Filho CA, de Camargo RE, Barbosa BD (2009) The growing importance of materials that prevent microbial adhesion: antimicrobial effect of medical devices containing silver. Int J Antimicrob Agents 34:103-110

Moreau C, Verges-Belmin V, Leroux L, Orial G, Fronteau G, Barbin V (2008) Water-repellent and biocide treatments: assessment of the potential combinations. J Cult Herit 9:394-400

Muynck DW, Ramirez AM, Belie ND, Verstraete W (2009) Evaluation of strategies to prevent algal fouling on white architectural and cellular concrete. Int Biodeterior Biodegradation 63:679-689

Nations S, Wages M, Canas JE, Maul J, Theodorakis C, Cobb GP (2011) Acute effects of $\mathrm{Fe}_{2} \mathrm{O}_{3}, \mathrm{TiO}_{2}, \mathrm{ZnO}$ and $\mathrm{CuO}$ nanomaterials on Xenopus laevis. Chemosphere 83:1053-1061

Nilsson S (1983) Atlas of airborne fungal spores in Europe. Springer-Verlog, Germany

Normal - 43/93 (1993) Misure colorimetriche su superfici opache, Raccomandazioni NORMAL, CNR centro studi di Milano e Roma sulle cause di deperimento e sui metodi di conservazione delle opere d'arte - ICR Istituto Centrale per il Restauro., Roma

Nugari PM, Pietrini MA (1997) Trevi Fountain: an evaluation of inhibition effect of water-repellents on cyanobacteria and algae. Int Biodeterior Biodegradation 40:247-253

Obuekwe CO, Badrudeen AM, Al-Saleh E, Mulder JL (2005) Growth and hydrocarbon degradation by three desert fungi under conditions of simultaneous temperature and salt stress. International 56(4):197-205

Pinna D, Galeotti M, Perito B, Daly G, Salvadori B (2018) In situ long-term monitoring of recolonization by fungi and lichens after innovative and traditional conservative treatments of archaeological stones in Fiesole (Italy). International Biodeterioration \& Biodegradation 132:49-58

Rebricova NI (1991) Some ecological aspects of protection of Old Russian wall paintings from microbiological deterioration. In: Agrawal OP, Dhawan S (eds) Biodeterioration of cultural property. Macmillan, New Delhi, India, pp 294-306

Ruffolo SA, La Russa MF, Malagodi M, Rossi CO, Palermo AM, Crisci GM (2010) ZnO and $\mathrm{ZnTiO} 3$ nanopowders for antimicrobial stone coating. Appl Phys A Mater Sci Process 100:829-834

Sawai J, Yoshikawa T (2004) Quantitative evaluation of antifungal activity of metallic oxide powders $(\mathrm{MgO}, \mathrm{CaO}$ and $\mathrm{ZnO})$ by an indirect conductimetric assay. J Appl Microbiol 96:803-809

Sharma D, Rajput J, Kaith BS, Kaur M, Sharma S (2010) Synthesis of $\mathrm{ZnO}$ nanoparticles and study of their antibacterial and antifungal properties. Thin Solid Films 519:1224-1229

Shilova, A.O, Khamova, V.T, Vlasov, Yu.D, Ryabusheva, V.Yu, Mikhal'chuk, M.V, Frank- Kamenetskaya, V.O, Marygin, M.A, Dolmatov, Yu.V (2009) Sol-gel synthesis and investigation nanocomposite protective biostable coatings. The Second Nanotechnology International Forum. Rusnanotech'09, pp 342-344

Strzelczyk AB (2004) Observation on aesthetic and structural changes induced in Polish historic objects by microorganisms. Int Biodeterior Biodegradation 53(3):151-156

Tiano P (2002) Biodegradation of cultural heritage: decay, mechanisms and control methods. Seminararticle, New University of Lisbon, Department of Conservation and Restoration. http://www.arcchip. cz/w09/w09_tiano.pdf. Access 5 Jul 2018

UNI 10859 (2000) Cultural Heritage-Natural and artificial stonesDetermination of water absorption by capillarity 
UNI 11207 (2007) Cultural heritage-Natural and artificial stones Determination of static contact angle on Laboratory specimens

Urzi C, De Leo F (2007) Evaluation of the efficiency of water-repellent and biocide compounds against microbial colonization of mortars. Int Biodeterior Biodegradation 60:25-34

Van der Werf ID, Ditaranto N, Picca RA, Sportelli MC, Sabbatini L (2015) Development of a novel conservation treatment of stone monuments with bioactive nanocomposites. Herit Sci 29:3
Winkler E (2002) Stone in architecture, properties and durability. In: 3rd Completely Rev. and Extended Edition. University of Notre dame, pp 14-25

Zhang L, Jiang Y, Ding Y, Daskalakis N, Jeuken L, Povey M, O’Neill AJ (2010) Mechanistic investigation into antibacterial behaviour of suspensions of $\mathrm{ZnO}$ nanoparticles against E. coli. J. Nanopart. Res 12(5):1625-1636 